\title{
Making a Difference for Children Affected by AIDS: Baseline Findings from Operations Research in Uganda
}

\author{
Laelia Zoe Gilborn, ${ }^{1}$ Rebecca Nyonyintono, ${ }^{2}$ \\ Robert Kabumbuli, ${ }^{2}$ Gabriel Jagwe-Wadda ${ }^{2}$
}

\footnotetext{
${ }^{1}$ Horizons Program, Washington, D.C., USA

${ }^{2}$ Makerere University, Department of Sociology, Kampala, Uganda
} 


\section{Acknowledgments}

This research is the result of our fruitful collaboration with PLAN International and its staff in Uganda and Washington, D.C., especially Justin Fugle, Noah Lukoda, Zaccheus Senabulya, Beatrice Muwa, John McDonough, and the counseling aides and field mobilizers in Luwero and Tororo. We are also grateful to the staff of National Community of Women Living with AIDS (NACWOLA), the Diocese of Luwero, and Grasslands Foundation for allowing us to learn from their wonderful work with families affected by AIDS. We are especially grateful to Ms. Beatrice Were, founder of NACWOLA, whose work inspired the experimental interventions in this study.

Dr. Edward Kirumira, head of the Department of Sociology, Makerere University, and other members of the Advisory Committee provide wonderful technical support and guidance. In addition, Stephen Boogere has kept the project going with his infinite energy in supporting the research team, as well as with his interviewing skills. We are very grateful to the talented graduates of the Department of Sociology who worked with the research team through long days of interviews in the field. Nancy Sloan and Scott Geibel of the Population Council and Jotham Mubangizi provide invaluable technical support with data management and analysis.

Thanks to those who reviewed and edited drafts of this report, including Margaret Dadian, Sam Kalibala, Ann McCauley, Naomi Rutenberg, and Ellen Weiss of the Horizons Program, and Sue Lucas of the International HIV/AIDS Alliance.

Most of all we wish to acknowledge and thank the individuals and families who participate in this research. They endure long interviews and share rich and personal information about their lives for the purposes of this research and ultimately toward a better understanding of how programs can improve the wellbeing of the millions of children and families affected by AIDS in Uganda, Africa, and the rest of the world.

USAID This study was supported by the Horizons Program. Horizons is funded by the U.S. Agency for International Development, under the terms of HRN-A-00-97-00012-00. The opinions expressed herein are those of the authors and do not necessarily reflect the views of the U.S. Agency for International Development.

Published in June 2001.

\footnotetext{
(2 Population Council

The Population Council is an international, nonprofit, nongovernmental institution that seeks to improve the wellbeing and reproductive health of current and future generations around the world and to help achieve a humane, equitable, and sustainable balance between people and resources. The Council conducts biomedical, social science, and public health research and helps build research capacities in developing countries. Established in 1952, the Council is governed by an international board of trustees. Its New York headquarters supports a global network of regional and country offices.
}

Copyright (C) 2001 The Population Council Inc. 


\section{Table of Contents}

Executive Summary 1

Introduction 3

The Impact of HIV/AIDS on Children 3

$\begin{array}{ll}\text { Methods } & 5\end{array}$

Study Goal and Objectives $\quad 5$

$\begin{array}{ll}\text { Study Design } & 6\end{array}$

Data Collection 6

Selection and Description of Study Participants $\quad 7$

$\begin{array}{ll}\text { Data Analysis } & 8\end{array}$

Baseline Findings $\quad 9$

Profile of the Adults $\quad 9$

Wellbeing of Parents and Planning for the Future 11

$\begin{array}{ll}\text { Guardians and Standby Guardians } & 15\end{array}$

$\begin{array}{ll}\text { Orphans and Children of PLHA } & 18\end{array}$

$\begin{array}{ll}\text { Program and Policy Implications } & 26\end{array}$

$\begin{array}{ll}\text { References } & 28\end{array}$ 

Making a Difference

\section{Executive Summary}

Many organizations provide support services to children affected by AIDS in East and southern Africa. Yet few of these programs have been evaluated. In Uganda, PLAN International, Makerere University, and the Horizons Program are collaborating on a study to assess the impact of an orphan support program on the physical, educational, and emotional wellbeing of children. The researchers are also studying a different program, called succession planning, in which children are reached before the death of the parent. This intervention includes helping parents to write wills and appoint guardians, creating family "memory books," and other activities that promote the longterm wellbeing of children. The baseline sample includes 353 parents who are HIV-positive, 495 children of people living with HIV/AIDS (PLHA), 233 orphans, and 326 current and standby guardians.

\section{Key Baseline Findings}

The impact of adult illness on children starts when a parent is diagnosed as HIVpositive or becomes ill with HIV/AIDS. Earlier research demonstrates that children orphaned by AIDS suffer physical, educational, and emotional setbacks. Baseline data from the current study demonstrate that these setbacks begin before parental death. For example, older children of PLHA $(\mathrm{n}=181$, ages $13-18$ years) report a decline in school attendance (26 percent) and performance (28 percent) when parents became ill.

Property grabbing is widespread, with women and children especially vulnerable. Among widows $(n=204)$ in this study, 29 percent say that property was taken from them when their husbands died, making them four times more likely than widowers to have experienced property grabbing. In addition, 21 percent of older orphans $(n=105$, ages 13-18 years) report experiencing property grabbing. This phenomenon further undermines the livelihood of households that are already weakened by the death of adult breadwinners. Despite valid concerns about property grabbing, only 10 percent of parents in this study have prepared written wills.

Many guardians are in poor health, and some are even infected with HIV/AIDS. Of the 51 guardians in this study who know their serostatus, one-third report that they are HIVpositive. Among parents who have not appointed a guardian, some report that the person they have in mind is HIV-positive, old, sick, or "likely to die before I do." As many as 40 percent of the HIVpositive parents in the sample look after orphans, meaning that they themselves are HIV-positive guardians. With elderly relatives and others in poor health comprising the "safety net," it is likely that many children will lose not one or two but a series of caregivers and relatives.

\section{Most older children want their parents to tell them the truth about being HIV-}

positive. Most older orphans who know that a parent died of AIDS say that parents should disclose their own serostatus to their children. Parents are also predominantly in favor of disclosing their HIV status to their children, but the majority ( 57 percent) have not done so, with many 
reporting uncertainty about how to discuss the topic. Parents and children who are in favor of disclosure say they feel this because they value honesty, talking about prevention, and being able to plan for the future.

Study participants say that material support is what they need most. When asked what they need in order to look after their children and foster children, both parents and guardians are most likely to say that they need material assistance or support.

\section{Selected Program and Policy Recommendations}

Reach children affected by AIDS before they become orphans. This research demonstrates that children living with HIV-positive parents need as many support services as orphans who live with guardians. One way to reach children early is to link programs for children affected by AIDS with care and support programs for PLHA. This link also strengthens the responsiveness of care and support programs by addressing a top concern of PLHA: the future wellbeing of their children.

Increase community awareness and accountability about the property rights of women and children. Although writing wills is not traditional in East and southern Africa, doing so may reduce property grabbing. However, the impact of will writing will be limited unless communities, leaders, and policymakers mobilize to uphold the property rights of women and children. National and religious inheritance laws may need to be enacted or strengthened. The International Convention on the Rights of the Child (signed by most African nations) is another useful tool for advocates of property rights for women and children.

Address the critical health needs of adult caregivers, including guardians. This study demonstrates that guardians, as well as HIV-infected parents, have critical health needs. Lifeprolonging care and support services for adults may minimize the toll of adult illness on children, increase the ability of adults to care for the children, and prolong critical adult-child relationships.

Improve capacity for adult-to-child communication, especially about difficult issues such as sex education, and parental illness and parental death. Parents and guardians say they need support and advice on how to discuss these difficult issues with children. It is important to respond to this demand because the psychosocial needs of these children are often overlooked. Older children benefit from honest disclosure of parental illness. Programs should explore ways in which parents, guardians, teachers, and religious leaders can develop adult-to-child communication skills.

Address material needs in AIDS-affected households. HIV-positive parents and guardians say that they urgently need material help to support their dependents in the face of illness. This support can take the form on income-generation projects, vocational training, food, clothing, home repairs, and the payment of school fees. 


\section{Introduction}

Many organizations and programs have begun to provide services and support to AIDS-orphaned children in East and southern Africa. Typical program components include the provision of school fees and supplies, supplementary feeding, home-visiting programs in which community members visit and assist affected children, and vocational training. However, few of these programs have been formally evaluated for impact.

This paper reports on baseline findings from a study of two programs for AIDS-affected children and their families implemented by PLAN International in the Luwero and Tororo districts of Uganda. One program, referred to as orphan support, provides educational, health, and nutritional assistance as well as other services to orphans. The second program, known as succession planning, reaches AIDS-affected children earlier, by helping HIV-positive parents prepare for their children's future through counseling, will-writing, appointing guardians, and other measures.

\section{The Impact of HIV/AIDS on Children}

As of the year 2000, over 15.6 million children ${ }^{1}$ had been orphaned by HIV/AIDS worldwide (Hunter and Williamson 2000). Of these, the vast majority are in sub-Saharan Africa. In Uganda alone, approximately 1.7 million children have been orphaned because of HIV/AIDS (UNAIDS 2000). A 1991 study indicated that 26 percent of children under the age of 18, in Rakai,Uganda, were orphans (MAP Network 1998). Although the incidence of new HIV infections has shown signs of reaching a plateau in Uganda, the number of orphans continues to grow. Experts suggest that orphanhood peaks seven to ten years after peaks in HIV seroprevalence occur. Interventions to help mitigate the impact of the epidemic on surviving children are urgently needed.

Children orphaned by AIDS are vulnerable in almost all aspects of their lives (Haworth et al.1991; Foster et al. 1995; Foster et al. 1997). Invariably, orphans witness the prolonged illness and death of one or more family members and suffer mental distress as a result. Some of the many challenges faced by orphans are loss of family, depression, increased malnutrition, lack of immunization and health care, lack of schooling, early entry into paid or unpaid labor, loss of inheritance through "property-grabbing," homelessness, early marriage, exposure to abuse, and increased risk of HIV/AIDS (Hunter and Williamson 1997).

Research in Kampala, Uganda, for example, revealed that 10 percent of households with no orphans found it difficult to pay school fees, compared to 47 percent of households with orphans (Muller and Abbas 1990). A 1996 study found that the main problems among Ugandan orphans were; inadequate shelter; inability to pay for school fees and supplies; lack of bedding, clothing and medical care; and the burden of having to care for younger siblings (Shuey et al. 1996). Another

\footnotetext{
${ }^{1}$ This figure refers to children under the age of 15 who have lost their mothers or both parents to HIV/AIDS. It does not include children who have lost only their fathers to HIV/AIDS.
} 


\section{Hgrizons}

study in Uganda suggests that orphans are at high risk of contracting HIV/AIDS and that female orphans are more at risk of infection than any other group in the population (personal communication, Dr. Gimono Wamai, April 1999).

The problems encountered by AIDS-affected children start before their parents die. According to Hunter and Williamson (1997) "Interventions to respond to AIDS orphaning should therefore include all children affected by HIV/AIDS, not just those whose parents have died from AIDS." A 1999 UNAIDS publication states, "If organizations wait until children become orphans, it is almost too late." Indeed, a review of programs to reach AIDS-orphaned children in East and southern Africa concludes that there is an urgent need to reach these children as soon as the parent is known or suspected to be terminally ill (Reid 1993). Relatively few programs, however, have instituted this approach or documented program outcomes and experiences.

HIV-positive parents and their children experience psychosocial distress because of uncertainty about the children's future. Children may suffer depression or develop behavioral problems at school (Hunter and Williamson 1997). Individuals working in care and support programs in East and southern Africa express concern about how to address emotional distress, including worry, depression, and loss. Methods for assessing psychosocial wellbeing in these settings are limited. However, it is likely that psychosocial distress among both HIV-positive parents and their children can be reduced by making provisions and plans for the children once orphaned (AHRTAG 1997).

The wellbeing of all children affected by AIDS depends in great part on the capacity of the community to support and raise them. Hunter and Williamson (1997) state: "The first and most important responses to the problems caused by HIV/AIDS come from the affected children, families, and communities themselves. The efforts of governments, NGOs, and donors are significant largely to the extent that they help children, families, and communities cope more easily with these problems." Yet few programs have focused on preparing and supporting willing guardians to take on additional child-care responsibilities.

Community support systems, especially foster families, are increasingly overburdened. Most African cultures are characterized by strong family and kinship networks that function as social support systems in times of need. Within this system, children who lose their parents are typically taken in by a relative, such as an uncle or aunt, as has been the pattern in East Africa.

However, as the prevalence of HIV increases and the number of orphans grows, this system is being challenged. Although most experts do not believe that the African family structure has "collapsed" under the weight of AIDS, there is no doubt that caregivers are increasingly burdened. Some adults refuse to take in orphans, while others continue to take them in despite their own poverty, advanced age, or ill health; cases of grandmothers or uncles inheriting several orphans are commonplace. Increasingly, orphans find themselves heading a household or belonging to a household headed by an older sibling under the age of 18 or by an elderly grandparent with no source of income. 


\section{Methods}

\section{Study Goal and Objectives}

This research is a collaboration among PLAN International, Makerere University, and the Horizons Program. The overall goal of the study is to identify effective ways to meet the needs of children affected by HIV/AIDS both before and after parental death.

The objectives of this study are to:

- Assess the impact of an orphan support program on child wellbeing.

- Explore the acceptability of a succession planning program in the Ugandan context.

- Assess the impact of succession planning on child wellbeing.

- Determine the impact of succession planning on adult wellbeing and on guardians' capacity to care for orphans.

For the purposes of this research, "child wellbeing" comprises school attendance and performance, physical health, material possessions (i.e., basic necessities), health, nutrition, psychosocial status, and exposure to negative events, such as abuse or property grabbing. "Capacity to care for orphans" is measured through guardians' self-assessment of their ability to provide for orphans, as well as household and socioeconomic characteristics.

\section{Study Design}

This is an ongoing quasi-experimental study with two study sites: the Luwero and Tororo districts of Uganda. There are three arms in each of the two study sites: one control arm and two experimental arms.

The experimental interventions for AIDS-affected children are being offered in addition to other HIV-related activities, which have been implemented by PLAN International/Uganda since 1992. These services include voluntary HIV testing and counseling, clinical services at health centers, home-based care, and HIV post-test clubs. They continue in both control and experimental sites. Most of these services are provided by volunteers, called counseling aides, trained and subsidized by PLAN.

\section{Experimental interventions}

Succession planning $(S P)$ : The primary target groups for succession planning are HIV-positive parents, their children, and standby guardians. SP includes counseling for HIV-positive parents on serostatus disclosure to children through memory books, support to appoint future "standby" guardians, legal literacy and will writing, assistance with school fees and supplies for children, 


\section{Hgrizons}

income-generation training and seed money, and community sensitization (with some variation in components by study site).

Orphan support $(O S)$ : The primary target groups for orphan support are children who have lost their parent(s) and guardians. OS consists of the following program components: improved access to health care services for orphans, school fees and supplies, health and sex education, vocational/agricultural training for older orphans, seed money and income-generation training for guardians and older orphans, training of guardians, and community sensitization (with some variation in components by study site).

The following is a simple representation of the study.

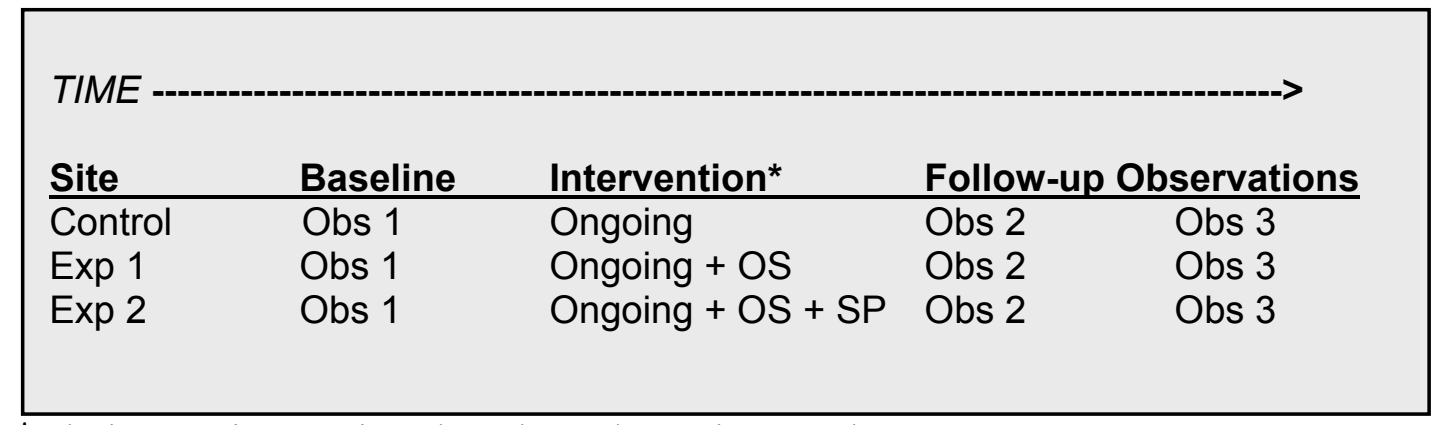

* The interventions continue throughout Observations 2 and 3.

The research design allows researchers to assess the impact of each of the experimental interventions separately by comparing post-intervention data to both baseline and control data, and also allows researchers to compare the relative impact of the two interventions.

This document reports on aggregated baseline data only (pre-intervention), collected in August/September 1999. The intervention had not yet begun. Thus, the results presented in this report are not disaggregated by study site or research arm.

\section{Data Collection}

The study participants consist of parents who are living with HIV/AIDS, current and standby guardians, children of PLHA, and orphans. The research team will follow the study participants over the course of the three observations (at one-year intervals in 1999, 2000, and 2001), yielding longitudinal information. Parents will be followed as long as they are alive and are able and willing to participate. Children, standby guardians, and current guardians will be followed up throughout the study, including beyond the death of the parent if it occurs during the study. 
Researchers collect the data through semi-structured interviews. College graduates, trained in sociology, conduct the interviews. Interviews take 45 minutes to an hour and are conducted in the participants' house with as much privacy as possible. Parents and guardians supply the data for younger children (age 5-12), while older children (age 13-17) are interviewed directly. Researchers also collect qualitative data between the second and third observations in the experimental arms. This includes in-depth interviews with program implementers and focus group discussions with program clients.

\section{Selection and Description of Study Participants}

Researchers recruited two types of households for the study: households with an HIV-positive parent (PLHA households) and households with an orphan (orphan households). All respondents were recruited through PLAN International's pre-existing services for PLHA.

In PLHA households, the research team interviewed up to four respondents, including an HIVpositive parent, a younger child (age 5-12), an older child (age 13-17), and a standby guardian. Children in these households will be referred to as children of PLHA. HIV-positive parents were drawn from PLAN's current list of home-based care clients. Only clients with children between the ages of 5 and 17 were eligible for the research. True random sampling could not be applied because of the geographical distance between clients and the fact that PLAN counseling aides had to guide researchers to clients.

The vast majority of eligible households participated in the study. The researchers asked parents to identify a standby guardian - the person most likely to care for the children in the future - and to name up to two children who would participate in the study (one in each age category). Thus, selection of children in households with multiple eligible children was not random but depended upon the parent's decision. Data were collected on school holidays, so this procedure should not have biased selection in favor of out-of-school children.

It was difficult to recruit standby guardians into the study. About two-thirds of parents (232 out of 353) named someone who might care for their children in the future. The research team attempted to interview all those named; however, only 99 (less than half of the standby guardians identified) could be reached. This was mainly because the standby guardians live at a considerable distance from the study sites.

In orphan households the research team interviewed up to three respondents: a guardian, a young orphan (age 5-12), and an older orphan (age 13-17). The researchers recruited the orphans and their guardians by contacting the children of deceased clients of the same home-based care services offered by PLAN, and the current guardians of these children. PLAN counseling aides led interviewers to the eligible households, and the vast majority agreed to participate.

Although the researchers did not intend to exclude orphans from child-headed households, no such households were found. In-depth interviews with local program staff revealed that there are relatively few child-headed households in the study areas. These reports agree with several other 


\section{Hgrizons}

studies in Uganda, which identified relatively few child-headed households (Monk 2000; Ntozi and Zirimenya 1999; Nalugoda 1997).

The total baseline sample consisted of 1,407 study participants: 728 children, 353 parents, and 326 standby or current guardians (Table 1). Together these respondents comprise 353 PLHA households and 227 orphan households.

Table 1 Description of the sample

\begin{tabular}{lccc}
\hline Study participants & Number & $\begin{array}{c}\text { Male } \\
\text { (\%) }\end{array}$ & $\begin{array}{c}\text { Sex } \\
\text { Female } \\
\text { (\%) }\end{array}$ \\
\hline HIV-positive parents (PLHA) & 353 & 24 & 76 \\
Younger children of PLHA (5-12 years old) & 314 & 46 & 54 \\
Older children of PLHA (13-17 years old) & 181 & 52 & 48 \\
Standby guardians & 99 & 57 & 43 \\
Younger orphans (5-12 years old) & 128 & 55 & 45 \\
Older orphans (13-17 years old) & 105 & 58 & 42 \\
Current guardians & 227 & 41 & 59
\end{tabular}

It should be noted that the African definition of "an orphan" is a child, usually under the age of 18 , who has lost one parent (single orphan) or both parents (double orphans). Children living in PLHA households may be single orphans because of the death of one parent. This study, however, categorizes these children as children of PLHA, whereas almost all the children categorized as orphans are double orphans living with a guardian.

\section{Data Analysis}

Data were analyzed using SPSS. Baseline analysis consisted mostly of frequencies and crosstabulations. To determine the significance of the difference in characteristics between different types of research participants (e.g., children of PLHA versus orphans), the researchers conducted cross tabulations and chi-square analyses. A $p$-value of less than 0.05 was used as the threshold for significance. 


\section{Baseline Findings}

\section{Profile of the Adults}

Adult respondents are predominantly from the Muganda, Atesot, and Japadhola tribes. Most adult respondents are Protestant or Catholic and a smaller percentage are Muslim or Seventh Day Adventists. Luganda is the most commonly spoken language, followed by Dhopahola, Itesot, and Swahili.

\section{Socioeconomic status}

Most adult respondents earn their income from farming, brewing, and trading. Table 2 shows that almost all adults, including HIV-positive parents, have access to land and grow crops. Standby guardians have somewhat less access to land and are somewhat more reliant on brewing and trading, as opposed to farming, for income. An index of socioeconomic status (SES) was developed based on a count of household possessions. Index items were foam mattress, separate kitchen, granary or store, lamp or lantern, radio, bicycle or other transport, and electricity. Current guardians scored the highest (3.57) on this SES index, followed by standby guardians (3.24) and parents (2.92).

Table 2 Socioeconomic profile of adult respondents

\begin{tabular}{lccc}
\hline & $\begin{array}{c}\text { HIV-positive } \\
\text { parents } \\
\mathbf{n = 3 5 3} \\
(\mathbf{\%})\end{array}$ & $\begin{array}{c}\text { Standby } \\
\text { guardians } \\
\mathbf{n = 9 9} \\
(\mathbf{\%})\end{array}$ & $\begin{array}{c}\text { Current } \\
\text { guardians } \\
\mathbf{n = 2 2 7} \\
\mathbf{( \% )}\end{array}$ \\
\hline Have access to land & 96.8 & 80.8 & 97.3 \\
Have access to 2 acres or more & 61.1 & 61.6 & 71.7 \\
Grow crops & 97.7 & 78.8 & 92.9 \\
Raise livestock & 76.2 & 67.7 & 76.5 \\
Roof material & & & \\
$\quad$ Iron/metal & 70.7 & 54.1 & 78.4 \\
$\quad$ Grass/thatch & 28.4 & 29.6 & 20.3 \\
$\quad$ Other & 0.9 & 16.3 & 1.3 \\
Send remittances & 26.2 & 43.4 & 36.3 \\
Receive remittances & 26.4 & 14.1 & 18.1 \\
Eat meat a few times a month or more & 23.2 & 29.3 & 36.9
\end{tabular}




\section{Hgrizons}

\section{Widowhood and foster parenting in study households ${ }^{2}$}

Data on household structure reveal a high rate of widowhood and a high proportion of adult respondents, including HIV-positive parents, caring for orphans (Table 3). Specifically, among the 353 HIV-positive parents, two-thirds are widowed and 40.4 percent indicate that they are taking care of at least one child that is not their own. Few parents are married (21.5 percent) and fewer are divorced (10.2 percent). Parents range in age from 22 to 73 years, with an average age of 39 years.

Among the 99 standby guardians, 11 percent are widowed and half are caring for at least one child that is not their own; 50 percent of standby guardians are married, and 11 percent are divorced. The standby guardians range in age from 16 to 80 years, with an average age of 39 years.

Among the 227 guardians, a fourth are widowed and 46.3 percent take care of at least one child that is not their own in addition to the child enrolled in the study. More than half (62.9 percent) of guardians are married, while 9.3 percent are divorced. Guardians are older on average than either parents or standby guardians. They range in age from 20 to 88 years, with an average age of 48 .

\section{Table 3 Widowhood and fostering among adult study participants}

\section{Widowed}

(\%)

HIV-positive parents
Standby guardians

Current guardians

66.9

11.0

25.1
Foster at least one child

(\%)

40.4

51.0

$46.3^{*}$

*In addition to the orphan enrolled in the study

\section{Burden of care for orphans by sex}

For most categories of subject participants, the ratio of males to females was fairly equal. Among HIV-positive parents, however, 75.9 percent were female. While this may be related to the method of sampling, it seems to reflect the reality in many AIDS-affected households. A household survey conducted in Uganda in 1999 revealed that AIDS-affected households are predominantly headed by women (Ntozi and Zirimenya 1999). This suggests that "single orphans" (children who have lost only one parent) are predominantly paternal orphans and that women, therefore, bear the bulk of the burden of caring for these single orphans.

\footnotetext{
${ }^{2}$ The word "fostering" in this report refers to the act of raising a child who is not one's own biological child because the child's parent(s) are too sick or deceased. In this context foster parents or guardians are almost invariably the grandparent, aunt, uncle, or other close relative of the child. This is in contrast to the terms "fostering" and "foster parent" as it is used in the United States.
} 
Standby guardians are predominantly male ( 60.3 percent of 232 guardians named by parents), whereas current guardians are predominantly female (59.0 percent). It is not entirely clear why there is this discrepancy in sex distribution. The standby guardian sample size was relatively small and may not be representative. The discrepancy may also suggest that although men are the expected and traditional providers, women are ultimately more likely to shoulder the responsibility for raising orphaned children.

\section{Wellbeing of Parents and Planning for the Future}

\section{Physical health}

Of the 353 HIV-positive parents interviewed, 63.4 percent state that they are in somewhat poor or very poor health and 90.3 percent report that they have been sick at least once in the past six months. All the parents in this study are HIV-positive. Among those parents with living spouses (n $=76$ ), the majority state that their spouse knows about their HIV status. The majority also say that they know or suspect that their spouse is HIV-positive as well. Overall, 50 percent of parents with living spouses state that their spouse is in somewhat poor or very poor health.

When asked who cares for them when sick, the HIV-positive parents in their study listed children (daughters more so than sons), their own parents, spouses, and siblings. However, 14.7 percent of respondents state that no one took care of them during their most recent illness, suggesting that some parents are socially isolated.

Parents need help with work and chores when they are sick: 80.2 percent said that they need help with child care and 81.3 percent needed help with other daily activities, such as farming or gardening; cooking and other housework; fetching water and firewood; fetching medicine or going to health centers; looking after livestock; selling, trading, or brewing; food shopping; and repairing the house. Assistance is available most but not all of the time. Older children, mothers, siblings, and brothers-in-law are the most common sources of assistance.

\section{Psychosocial issues: concerns about children}

Almost all HIV-positive parents (91.5 percent) express worries about their children's future. As shown in Table 4, parents express the greatest concern about their children's access to education, food, and the basic necessities of survival. They also worry about their children being exploited or becoming the victims of property grabbing, and about the lack of an appropriate guardian. Table 4 presents the major concerns volunteered by parents. 


\section{Hgrizons}

Table 4 Parents' concerns about children's future

\begin{tabular}{lc}
\hline & $\%$ \\
\hline Education & 56.9 \\
Food/clothes/survival & 53.0 \\
Property grabbing/exploitation & 29.5 \\
Lack of adult guardian & 23.8 \\
Physical shelter & 20.1 \\
Child's poor health & 14.7 \\
Child unable to earn money & 9.6 \\
Emotional suffering & 9.6
\end{tabular}

\section{Other psychosocial issues among parents}

Most parents (61.2 percent) have other worries as well. In order of priority, parents worry about their own declining ability to work or support themselves, their own mortality, deteriorating living conditions, and being stigmatized or treated badly for being HIV-positive.

Over 95 percent of parents named at least one person in whom they could confide about their worries. Common sources of emotional support include close family members (parents, sibling, older children), friends, and counseling aides. The most important forms of support provided are emotional support, material assistance, practical advice, assistance with getting medical treatment, and help with chores and other activities of daily living. Nevertheless, more than half of parents state that there are certain people with whom they avoid talking about health-related worries. (See also "Secrecy, stigma, and discrimination," page 15).

\section{Wills and property}

Almost half of adult respondents in this study report that property grabbing is a problem in their community. Property grabbing is a phenomenon whereby inherited property is taken from the surviving family members and heirs to whom it rightfully belongs. Adult respondents believe that property grabbing after the death of a spouse is a greater problem for women (48.1 percent) and orphans (47.3 percent) than it is for men (14.1 percent). Paternal relatives are thought to be the most likely to steal inherited property, but there are also some fears that other community members and maternal relatives will do so.

More than one in five parents fear that their property will not be distributed as they intend. Most are concerned specifically about property grabbing by paternal relatives ( 70.4 percent,) and, to a much lesser degree, by community members (13.6 percent).

These perceptions and fears about property grabbing are justified. More than a quarter of widowed parents ( 26.2 percent) say they lost property when their spouse died. Female widows are four times 
more likely to have experienced property grabbing than are male widowers ( 28.8 percent vs. 7.1 percent, $p<0.05$ ). Also, 21 percent of older orphans report that property was taken from them after the death of their parent(s).

Despite substantial concerns about and experience with property grabbing, only 10.2 percent of parents have actually written wills. This is slightly higher than in the general population of Uganda where only 5 percent of people who die leave written wills (WLEA 1997). Men are significantly more likely than women to have written wills (18.8 percent vs. 7.5 percent, $p<$ $0.05)$. Key findings on property grabbing and wills are summarized in Table 5.

\section{Table 5 Property grabbing and wills}

\begin{tabular}{lc}
\hline & $\%$ \\
\hline Parents with written wills & 10.2 \\
Parents without written wills & 89.8 \\
Widowed men who experienced property grabbing & 7.1 \\
Orphans who experience property grabbing & 20.1 \\
Widowed women who experienced property grabbing & 28.8
\end{tabular}

Knowledge of Ugandan property and inheritance laws and how they protect the property rights of women and children is limited. Ugandan law upholds the rights of women and children to inherit property, with or without a written will. (These rights are upheld by the Succession Act as amended by the Succession Decree in 1972 and in the Land Act of 1998.) Nonetheless, only 76.5 percent of parents in this sample know that children have a right to inherited property in the absence of a will, and even fewer (63.1 percent) know that widows are entitled to inherited property in the absence of the will.

\section{Appointing guardians}

Most (86.7 percent) HIV-positive parents believe that there is a need to make explicit arrangements to appoint a guardian in order to ensure future care for their children, to reduce children's anxiety, to allow guardians to prepare, and to reduce their own (parents') worries. However, only half of HIV-positive parents (51.7 percent) have arranged for a guardian. Among those with no formally appointed guardian, 28.6 percent believe that someone would care for the children anyway. The rest state that they know of no one who is willing and able, they have not thought about it, they are still in good health, or they do not want to reveal their HIV serostatus. Concern about revealing serostatus highlights how some parents feel the need for secrecy about being HIV-positive and how this can limit their ability to plan for their children's future. Other parents are unable to appoint a guardian because the person they have in mind is ill, old, or perhaps even HIV-positive. This demonstrates that the safety net for children orphaned by AIDS is itself penetrated and weakened by HIV infection among guardians. 


\section{Hgrizons}

According to earlier research, familiarity with the guardian before the parent dies is associated with greater emotional wellbeing once a child is living in a foster household (Nampanya-Serpell 1998). In this study, about half of parents who have appointed a standby guardian report that all their children know of the arrangement. Their children generally know the appointed guardian well and see him/her a few times a week or more (62.0 percent). In some cases the standby guardian is a member of the child's own household. Others (13.7 percent), however, hardly know or see their standby guardians.

\section{Disclosure of HIV status within the family: parents' perspective}

The majority of parents (61.2 percent) state that some or all of their children know that the parent is are HIV-positive. Yet fewer than half (43 percent) of parents report having actually spoken to their children directly about being HIV-positive. According to parents, the other children learn through gossip and by observing their parents' ill health, need for medical services, or death.

Parents who disclosed their HIV status to at least one child were asked to reflect on this decision and its outcomes. The great majority (91.3 percent) think that it was a good idea to talk to their older children about being HIV-positive. Seven parents (4.7 percent) said that disclosure had both good and bad results; only three parents reported that disclosure has caused problems and is not a good idea.

\section{Parents' views on disclosure of HIV status to children}

Reasons in favor:

- Children will know the truth.

- Children can avoid HIVIAIDS themselves.

- Children can prepare emotionally.

- Children can prepare practically.

- Children will know what to do when parent(s) die.

\section{Reasons opposed:}

- It will worry or upset the children.

- It is too difficult to discuss.

- Children may not be able to keep a secret.

The majority of the parents who have not disclosed their HIV status to their children feel that it would be a good idea to do so (68.3 percent), at least if the children are old enough. One in four (26.1 percent) are opposed to telling their children. While parents are predominantly in favor of disclosure, there is a widely held opinion that some children are too young to be able to handle the information.

Overall, parents are in favor of disclosure to children who are old enough to handle the truth but do not always know how to discuss this difficult issue. The arguments for and against disclosure are summarized below. Perhaps the strongest argument in favor of parental disclosure is that older children view it positively. This is further discussed in the section "Disclosure of HIV status within the family: children's perspective" (page 22). 


\section{Secrecy, stigma, and discrimination}

Although parents were not asked explicitly about being stigmatized and discriminated against for having HIV/AIDS, their secrecy about HIV suggests that they fear potential mistreatment.

As stated earlier, more than half (57.8 percent) of parents state that there are certain people (most commonly neighbors, community members, siblings, in-laws, friends and parents) with whom they cannot talk about their health-related worries because "they don't take my problems seriously;" they may gossip to others; they may not be able to help; or they may become excessively worried. More women than men report that there are people in their lives with whom they cannot discuss their HIV status (62.5 percent vs. 47.0 percent, $p<0.05)$; this suggests that perceived stigma, and perhaps enacted stigma and discrimination, have a greater impact on women. Thus, HIV-positive women (who are also more likely than men to be widowed) may be or feel particularly isolated.

As noted earlier, a reluctance to disclose their health status hinders a number of parents from appointing guardians for their children. In explaining why they do not tell their own children or seek support from neighbors/friends, some parents state, "They can't keep a secret." Again, this stated need for secrecy is more pronounced among women.

The phenomenon of property grabbing can also be construed as a form of discrimination against families affected by AIDS. However, it is not exclusive to AIDS-affected families and may be first and foremost a sign of discrimination against women and children.

\section{Programming needs}

Aside from writing wills and appointing guardians, fewer than one in five (19.5 percent) parents have taken other actions to address their worries, such as increasing their income. When parents were asked what they would like to do to ensure the wellbeing of their children, their responses emphasized acquiring productive resources and improving their economic situations, thereby indicating material needs.

\section{Guardians and Standby Guardians}

\section{Profile of guardians}

Current guardians interviewed are mostly aunts/uncles (41.6 percent) or grandparents (44.7 percent). Another 5.3 percent of guardians are siblings of the orphan and 4.4 percent are stepparents. Standby guardians who were reached for an interview are mostly either aunts/uncles 


\section{Hgrizons}

(53.9 percent) or grandparents (36.9 percent). Both standby and current guardians are more likely to be paternal than maternal relatives. Of note: standby guardians are more often male than female (60.3 percent vs. 39.7 percent), whereas the majority of current guardians are female (58.6 percent).

\section{Physical health}

Thirty percent of guardians state that they are in somewhat poor or very poor health and 79.0 percent have been sick in the past six months. (On average, current guardians are older- 48 years old - than parents and standby guardians.) This suggests that many guardians have physical limitations when it comes to earning money, growing food, and tending to orphaned children.

Baseline data suggest that an alarming proportion of guardians are themselves infected with HIV/AIDS, raising concerns about their long-term ability to care for orphans. Although only 22.7 percent of current guardians knew their HIV status (51), one-third (17) of those reported that they were HIV-positive. In addition, some parents who have not arranged for a guardian explained that the appropriate person is either sick, old, HIV-positive, or "likely to die before I do." As further evidence of AIDS penetrating the "safety net" (for orphans), 40 percent of HIV-positive parents are looking after orphans or other foster children and are thus HIV-positive guardians themselves.

\section{Preparedness of standby guardians}

Only 19.2 percent of standby guardians feel completely prepared to foster an additional child. Most standby guardians (90 percent) worry about their future responsibilities. More than half of standby guardians (51.5 percent) say they are somewhat or very unprepared to take care of orphaned children. They doubt their ability to feed the children well enough (48 percent) and to send them to school (70 percent). Other worries include lack of money for school fees, clothes, food and other items for the child; other financial concerns; feeling overwhelmed; caring for a sick child; and their own physical limitations or poor health.

Despite these concerns, 94 percent of standby guardians report that they have agreed to take care of the children when the need arises. More than two-thirds of standby guardians (69.7 percent) say that they have discussed this decision with the children's parent(s).

Most standby guardians are already actively involved in assisting the affected households, with 84.8 percent saying the parent has needed material support for things like food, school supplies, and clothing or blankets. Additionally, 78.8 percent say they help the parent with such things as cooking and housework, fetching medicine or taking the parent to the health center, gardening or doing farm work, caring for children, fetching water and firewood, doing home repair or construction, and buying things at the market.

These needs pose challenges for standby guardians. For example, 76.8 percent state that they do not have the resources to provide all the assistance that the children need. Other problems standby 
guardians face include being pressed for time, worrying about their future burdens, and having too many other responsibilities. A few state that their own family resents their involvement with the affected family.

Only 20 percent of standby guardians report that they have made any special preparations for their future fostering responsibilities. Most preparations focus on improving their ability to provide for their growing households materially, such as trying to grow more food.

\section{Current guardians' capacity to care for orphans}

The capacity of guardians to care for orphans is undoubtedly affected by the number of able-bodied adults in the household and the number of dependent children. The fact that about a third (34.4 percent) of guardians are either widowed or divorced and that about half ( 46.3 percent) care for more than one orphan indicates a high dependency ratio in orphan households. Furthermore, many guardians are elderly or in poor health.

Despite these challenges, measures of child wellbeing suggest that, among the study participants, the guardians are doing at least as well as, if not better than, the HIV-positive parents in the study in educating, feeding, and tending to the needs of the AIDS-affected children in their households.

More than two-thirds (69.2 percent) of current guardians feel that they are able to feed the children adequately. Sixty-one percent of guardians report the orphaned children for whom they are responsible go to school consistently. Enrollment rates among orphans suggest that they have good access to education (see page 18). The material wellbeing of orphan children-measured through questions about whether the child has a blanket, shoes, spare clothes, school uniform, notebook and pens/pencils - is the same or better than the material wellbeing of children in PLHA households (see Table 7). Most guardians (70 percent) report that they have enough time to attend to the problems faced by their foster children.

The vast majority of older orphans (76.2 percent) say they are happy, comforted, or relieved to be in their foster households. However, a minority of older orphans report that things changed for the worse when they moved into the guardian's household. For example, 14.3 percent report an increase in household responsibilities, 11.4 percent report a reduction in personal food and clothing, and 8.6 percent report a reduction in household resources.

\section{Programming needs identified by guardians}

When asked what services would help them to better provide for foster children, current and standby guardians prioritize material assistance and means of improving their income. They also need advice and training on how to talk to and counsel children who have been affected by HIV/AIDS. 


\section{Hgrizons}

\section{Orphans and Children of PLHA}

\section{Education}

The majority of the children in the study are enrolled in school (91 percent of younger children of PLHA, 92 percent of younger orphans, 89 percent of older children of PLHA, and 96 percent of older orphans). ${ }^{3}$ The greatest imbalance in school enrollment by sex was found among older children in orphan households (females were less likely than males to be enrolled in school) but the difference is not significant. Additionally there are no significant differences in enrollment rates when the sample is compared by age group or type of household (i.e., child of a PLHA vs.

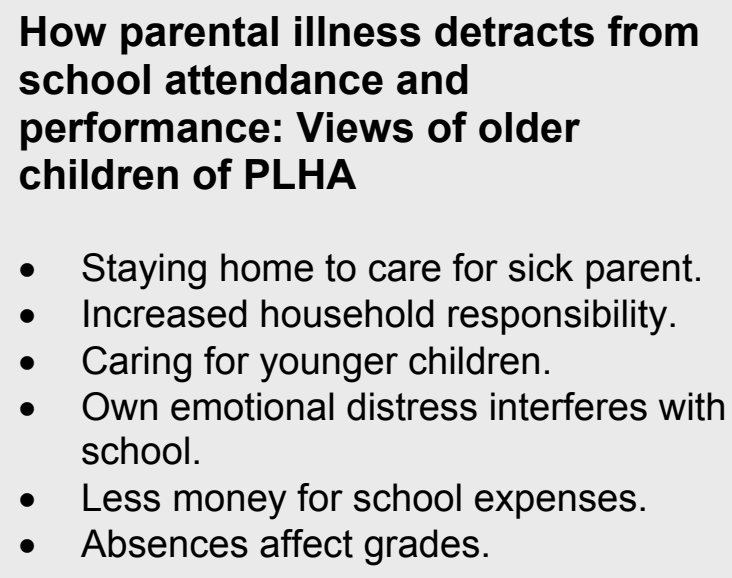

- $\quad$ Staying home to care for sick parent.

- Increased household responsibility.

- Caring for younger children.

- Own emotional distress interferes with school.

- Less money for school expenses.

- Absences affect grades. orphan).

Although the difference is not statistically significant, day-to-day attendance is lower for older children in PLHA households than for orphans - 88.6 percent of older orphans attend school most or all of the time compared to 80.1 percent of older children of PLHA. This suggests that adult illness may be taking a toll on the education of older children. Children of PLHA may be helping at home to compensate for adult illness in the family. Indeed, these children confirm that adult illness has an impact on their schooling. When researchers asked older children of PLHA what impact parental illness had on their education, 26.0 percent of children reported that their attendance declined and 27.6 percent reported that their school performance declined as a result of parental illness. They say that this is a result of staying home to care for sick parents, an increase in household responsibilities (including caring for younger children), emotional distress (worry, sadness, or declining motivation), and being unable to pay school fees.

The impact of parental illness on schooling is especially important in light of findings that when asked what makes them happy, children are very likely to report "being in school" and "being with other children." Conversely, missing school and doing poorly in school are associated with feelings of sadness and social isolation.

The fact that 21.9 percent of older orphans report that their school attendance improved when they moved into the foster household suggests that while parental illness can hinder access to school by

\footnotetext{
${ }^{3}$ Recent legislation mandating universal primary education (and waiving school fees) and PLAN International's ongoing programs in education and school construction support school attendance in the study area.
} 
children of PLHA, guardians may be able to put older children back in school. Few orphans reported that their attendance worsened upon joining the guardian's household.

\section{Chores and work}

Like most children in Uganda or in Africa, the children in this study have many household responsibilities. Among older children, those in PLHA households have more responsibility for younger children than those in orphan households (20.4 percent vs. 14.3 percent). They also have significantly more responsibility for sick family members than do their peers in orphan households (19.9 vs. 10.5 percent, $p<0.05$ ). Almost no younger children and only 8.4 percent of older children work for wages, with no significant differences between orphans and children of PLHA.

\section{Health and nutrition}

Findings show that the health status of children of PLHA is similar to that of orphans (Table 6). Among older children of PLHA and orphans, 10.5 percent report that they are in somewhat poor or very poor health. Younger children, especially orphans, are in somewhat poorer health than older children; 15.4 percent of children of PLHA and 18.8 percent of orphans are reported to be in somewhat poor or very poor health.

Hunger is a problem for many children in the study. More than a third of older children of PLHA (34.3 percent) and of older orphans (37.1 percent) say "there are some days when I don't get enough to eat." Nearly a fifth (19.6 percent) of older children and 15.2 percent of younger children report not getting enough to eat a few times a week or more often. Older orphans are the most likely to report not getting enough to eat a few times a week or more (24.8 percent).

When comparing younger children of PLHA with younger orphans, there are a few indications that orphans may have greater access to food than children whose parent(s) are living with HIV/AIDS. Younger orphans are significantly more likely than their non-orphaned peers to receive meat a few times a month or more (40.6 vs. 25.5 percent, $p<0.05$ ). 
Table 6 Health and nutrition profile of children

\begin{tabular}{lcccc}
\hline & \multicolumn{2}{c}{ Age $\mathbf{5 - 1 2}$} & \multicolumn{2}{c}{ Age 13-17 } \\
& $\begin{array}{c}\text { Young } \\
\text { children } \\
\mathbf{n = 3 1 4} \\
\mathbf{( \% )}\end{array}$ & $\begin{array}{c}\text { Young } \\
\text { orphans } \\
\mathbf{n = 1 2 8} \\
\mathbf{( \% )}\end{array}$ & $\begin{array}{c}\text { Older } \\
\text { children } \\
\mathbf{n = 1 8 1} \\
\mathbf{( \% )}\end{array}$ & $\begin{array}{c}\text { Older } \\
\text { orphans } \\
\mathbf{n}=\mathbf{1 0 5} \\
\mathbf{( \% )}\end{array}$ \\
\hline $\begin{array}{l}\text { Child does not get enough to eat } \\
\quad \text { Every day }\end{array}$ & 2.9 & 0.8 & 2.8 & 1.9 \\
$\quad$ A few times a week or more (cumulative) & 15.0 & 9.4 & 16.6 & 24.8 \\
$\quad$ A few times a month or more (cumulative) & 27.1 & 15.6 & 25.4 & 37.1 \\
Health status & & & & \\
$\quad$ Somewhat poor or poor & 15.4 & 18.8 & 10.5 & 10.5 \\
$\quad \begin{array}{l}\text { Sick in last 6 months } \\
\text { Meals eaten every day }\end{array}$ & 62.1 & 70.3 & 60.8 & 46.7 \\
$\quad$ Morning tea/breakfast & 49.7 & 58.4 & 52.8 & 54.3 \\
$\quad$ Lunch & 90.8 & 93.0 & 88.4 & 87.6 \\
$\quad$ Supper & 96.8 & 94.5 & 95.6 & 95.2 \\
Eats meat at least a few times per month & 25.5 & 40.6 & 36.3 & 41.0 \\
Drinks milk at least a few times a month & 35.8 & 40.6 & 38.1 & 41.0
\end{tabular}

\section{Material wellbeing}

The researchers developed an index to assess the material wellbeing of each child. Index items were blankets, shoes, a spare set of clothes, school uniform, notebook, and pens/pencils. One point was given for each item the child had, for a minimum score of 0 and a maximum of 6 .

The average scores were as follows: younger children of PLHA: 3.38; younger orphans: 3.59 ; older children of PLHA: 3.55; older orphans: 3.75 . These scores suggest that children in orphan households are slightly better off in terms of material wellbeing. The same is true when the index is reduced to include only school supplies (uniform, notebook, and pens/pencils), suggesting that children in orphan households have somewhat greater access to school supplies. As shown in Table 7, older children in orphan households have more access to notebooks (76.2 percent vs. 66.3 percent) and school uniforms (67.6 percent vs. 57.5 percent) than do their peers in PLHA households, but these differences are not significant. 


\begin{tabular}{lcccc}
\multicolumn{5}{l}{ Table 7 Access to selected items by children of PLHA and orphans } \\
\hline & Blanket & Shoes & $\begin{array}{c}\text { School } \\
\text { uniform } \\
\text { (\%) }\end{array}$ & Notebook \\
& $\mathbf{( \% )}$ & $\mathbf{( \% )}$ & $\mathbf{( \% )}$ \\
\hline Younger children of PLHA & 41.4 & 22.6 & 61.5 & 73.6 \\
Younger orphans & 47.7 & 23.4 & 66.4 & 79.7 \\
Older children of PLHA & 58.0 & 38.1 & 57.5 & 66.3 \\
Older orphans & 61.9 & 30.5 & 67.6 & 76.2
\end{tabular}

\section{Psychosocial issues}

The interview included a number of questions to determine the psychosocial impact of parental illness and orphanhood on children. When asked how happy they were, the majority of older children responded that they were as happy as or happier than their peers $(84.5$ percent of older children of PLHA and 82.9 percent of older orphans). Among younger children, 95.2 percent of those in PLHA households and 93 percent in orphan households are described as happy or happier than their peers. Further questions, however, give more insight into the psychosocial issues that are relevant for children affected by AIDS.

When asked if they feel different from their peers, 19.9 percent of older children of PLHA and 35.2 percent of older orphans say "yes." These children explain that they feel different because they have a sick or deceased parent, have "poor" clothes and shoes, and/or are not attending or doing as well in school.

When asked explicitly about parental illness, older children of PLHA say it causes them to worry (34.8 percent), feel sad (30.4 percent), and feel alone or isolated ( 5 percent). At the same time, 17.1 percent of older children do not acknowledge experiencing any emotional impact. This may reflect denial, ignorance about the nature of the illness, or a determination to overcome adversity rather than genuine indifference to parental illness. Older children also cite several social and economic effects, including increased poverty (26.6 percent), household responsibilities (18.6 percent), and childcare duties (11.6 percent). 


\section{Hgrizons}

The study findings do not suggest a pronounced decline in psychosocial wellbeing once children are orphaned. The vast majority of older orphans (76.2 percent) say they are happy, comforted, or relieved in their foster families; however, 13.5 percent say they feel sad. Explanations include both bereavement and feeling uncomfortable with the guardians. A minority (14.3 percent) of older orphans report that in the guardian-headed household they have more household responsibilities, 11.4 percent report having less personal food and clothing, and 8.6 percent report having reduced household resources (than when they were still living with their parent).

Older children were asked what, if anything, makes them feel sad. The most common responses include being punished or abused (verbally or physically), and sickness and death in the family. Some respondents also mention being sick themselves and missing or doing poorly in school. According to adult respondents, younger children are also saddened by being punished or abused, being hungry, being sick, and by sickness and death in the family. Children of PLHA mention punishment and abuse just as frequently as orphans do.

Prior research has demonstrated that being separated from siblings is a source of distress for younger orphans (Nampanya-Serpell 1998). The current study suggests that the same may be true of older children. In our sample, 64.3 percent of older orphans are separated from one or more of their siblings. When asked explicitly about how they felt about being apart from their siblings, older orphans $(n=64)$ report feeling sad $(43.8$ percent $)$ and feeling isolated (17.2 percent).

Interviews with both children and adults emphasized the importance of sports and recreation, school, being with other children, and spending time with family (including guardians and their families) in maintaining happiness.

Older children generally have strong opinions in favor of parental disclosure of HIV status. The opportunity for honest discussion and to plan for the future is likely linked to better psychosocial wellbeing in the long term among these children. This is discussed in the next section in detail.

\section{Disclosure of HIV status within the family: children's perspective}

Among the 181 older children of PLHA, 81.7 percent are aware that their parent has some health problem. But fewer than a third (30.4 percent) said that their parent is HIV-positive or "has AIDS" when asked what was causing their parent's sickness. Only about a fourth of the children report that they were told explicitly by their parents that they were HIV-positive. The vast majority of those who were told ( 88.0 percent $)$ said they felt it was a good idea for parents to disclose their HIV status to their children; only (8.0 percent) were opposed to parental disclosure. ${ }^{4}$

\footnotetext{
${ }^{4}$ In order to avoid a situation whereby the interview or research process would cause a child to learn of a parent's HIV status for the first time, questions about parent's health and about disclosure were handled in the following manner. Older children were first asked whether their parent had any health problem. If the child responded no, the entire series of questions was skipped. If the child responded yes, s/he was then asked, in an open-ended question, what it was that the parent was suffering from (now or at the time of death). Only if the child responded that the parent was HIV-positive was s/he then asked how s/he found out and other questions about the impact of parental HIV/AIDS and of disclosure on the child.
} 
It is not clear why there is a discrepancy between the proportion of parents who report that they disclosed their HIV status to any of their children (43 percent) and the proportion of older children who report parental disclosure (27.6 percent). It may be that parents were disclosing to some children, but not necessarily to the child enrolled in the study. Lower reporting of disclosure by children may also indicate denial or secrecy on the part of the child about the parent's health.

Among the 105 older orphans, about half (51.4 percent) state explicitly that a parent had AIDS when he or she passed away. Only 19.0 percent of older orphans report having discussed this with their parents directly. Again, the majority of those who knew their parents were HIV-positive were in favor of parental disclosure to children. This was the same for those who experienced parental disclosure (16 out of 20 or 80 percent) and those who did not ( 27 out of 33 or 81.8 percent). Other ways that the orphans in this study discover that a parent is HIV-positive are when a relative tells them, when they become aware through community gossip, or when the parent was sick or needed health services. A few orphans learned only at the time of the parent's death. One-third (34.3 percent) of orphans state that they do not know what was wrong with their parent and the rest cited some other cause of death.

Parental disclosure of HIV status to children is an emotionally complex process for the entire family. Overall, however, children view disclosure positively. Most older children whose parents have discussed their HIV status with them feel that this was a good idea. Older children value these discussions because they help them know the truth, avoid AIDS, and prepare mentally and practically for the future. In addition, parent-child dialogue can facilitate the appointment of a guardian and the child can participate in this process. These responses all suggest that in the long run, parental disclosure contributes to the psychosocial wellbeing of older children and that secrecy and denial in families may detract from psychosocial wellbeing.

\section{AIDS prevention knowledge}

Most older children (81.8 percent) believe that they will avoid contracting AIDS themselves. However, AIDS prevention knowledge is limited among the older children in this study, with 10.2 percent of older children unable to name a single way to avoid AIDS (Table 8). Sources of information on HIV/AIDS are also limited. Only 42.8 percent of all older children have ever spoken with their parents about AIDS prevention. Other sources of information on HIV/AIDS are teachers (40.6 percent), friends (9.1 percent), and aunts/uncles (7.7 percent). 


\section{Hgrizons}

\begin{tabular}{lc} 
Table 8 Older children and knowledge of HIV-prevention strategies \\
\hline Strategies & $\%$ \\
\hline Abstinence & 56.6 \\
Condoms & 40.2 \\
Avoidance of sharp objects & 26.6 \\
Mutual monogamy & 19.2 \\
Unable to mention one method & 10.2
\end{tabular}

\section{Stigma and discrimination}

Several studies in Africa have shown that orphans are often stigmatized and discriminated against, both within foster households and in the larger community. Typically these studies show poorer nutrition and lower school enrollment among orphans (Kamali et al. 1996; Nalugoda 1997; Sengendo and Nimbi 1997; Elmore-Meegan et al. 1999). The researchers questioned the study participants for their views on these issues. More than a quarter of adults report that children of PLHA and orphans are sometimes treated differently because of having AIDS is in the family. About 17 percent of older children believed that AIDS-affected children are treated differently.

Adult respondents identify the following people as being the most likely to discriminate against HIV-positive children: the community in general, other children, guardians, and stepparents. Stepsiblings and other children in the household are mentioned less frequently. ${ }^{5}$ When asked about specific forms of abuse, 30.2 percent of adults respondents say AIDS-affected children are sometimes verbally abused or teased, while a fourth (24.3 percent) perceive that AIDS-affected children are neglected, 16.6 percent believe they are physically abused, and 6.9 percent believe they are sexually abused.

Information was also sought about AIDS-related mistreatment actually experienced by the children in the study (i.e., enacted stigma and/or discrimination). According to adult respondents, 10.2 percent of younger children of PLHA and 6.3 percent of younger orphans have been mistreated because of having AIDS in the family. Among older children, 6.2 percent of children of PLHA and 7.7 percent of orphans report that they have been mistreated for this reason. These results suggest that mistreatment of AIDS-affected children is the exception rather than the rule but is prevalent enough to warrant training the community to be more sensitive and monitoring children for signs of abuse.

Prior research indicates that orphans in foster households are sometimes "discriminated against" or neglected in the sense of having less access to school, food, and material goods than do the natural children of guardians (Lusk, Huffman, and O'Gara 2000), so researchers asked several questions

\footnotetext{
${ }^{5}$ Because the respondents include standby and current guardians, there may be underreporting of neglect or mistreatment of orphans by guardians or by other children in the household.
} 
about this topic. A small percentage of older orphans feel they are underfed (11.4 percent) or receive fewer material goods (9.5 percent), compared to other children in the household; most of these children feel that this is specifically because of their orphan status. The majority of orphans, however, feel they are provided for in the same way as other children in the family.

Although current and standby guardians express concerns about the demands of caring for children who are in poor health, there is little evidence that these adults stigmatize such children or irrationally fear the children of PLHA in their care. 


\section{Program and Policy Implications}

Baseline data from this study demonstrate a need for interventions to reach children affected by HIV/AIDS, including orphans and children living with HIV-positive parent(s). The data also indicate that adult caregivers, both parents and guardians, have needs of their own that must be addressed in order to improve and prolong their capacity to care for children affected by HIV/AIDS. The following recommendations that emerged from the study are relevant for government bodies, NGOs, religious organizations, communities, and international agencies.

Reach children affected by AIDS before they become orphans. The impact of parental HIV/AIDS on children starts when a parent is diagnosed or becomes ill with HIV/AIDS. This is especially true for older children, whose education may suffer when they stay home from school to do chores and to care for younger children and for sick adults. One way to reach children early is to link programs for children affected by AIDS with care and support programs for PLHA, which provide a natural group of parent beneficiaries. This link also strengthens the responsiveness of care and support programs by addressing a top concern expressed by PLHA: the future welfare of their children.

Increase community awareness and accountability about the property rights of women and children. This is especially important because most surviving parents and guardians are female. Although it is not traditional in East and southern Africa, will writing may reduce property grabbing. Because women are vulnerable to property grabbing and often outlive their husbands, it is important to train men as well as women to write effective wills. The impact of will writing, however, will be limited without efforts to mobilize communities and leaders to uphold women's and children's property rights. Community groups and leaders (local government officials, clan leaders, spiritual leaders, etc) should help to enforce property rights, which may require enacting or strengthening national and religious inheritance laws. The International Convention on the Rights of the Child (signed by most African nations) is another useful tool for advocates.

Address the critical health needs of adult caregivers, including guardians. Prolonging adult-child relationships should be a top priority of programs for children affected by AIDS. This study demonstrates that guardians as well as parents have critical health needs. Life-prolonging care and support services for adults may minimize the toll of parental illness on children, improve their access to school, and delay orphaning. These services should be extended to guardians to prolong their ability to care for orphans.

Improve adult-to-child communication and provide counseling on such difficult issues as parental illness, parental death, and sex education. Parents and guardians alike articulate a need for support with and advice about discussing difficult issues with children. It is important to respond to this demand because the psychosocial needs of these children are often overlooked. Older children benefit from disclosure and honesty about parental illness. Memory books - albums with photos, anecdotes, and other family memorabilia — provide a good medium 
for disclosure and planning for the future. Other means for developing communication skills among parents, guardians, teachers, and religious leaders should be explored, including skills in educating youth about AIDS and reproductive health.

Address the material needs of AIDS-affected households, including those headed by HIV-positive parents and by guardians. Whether in the form of income-generation projects, vocational training, food, clothing, home repairs, or school fees, HIV-positive parents and guardians are very vocal about the need for material support to provide for their many dependents.

\section{Improve the morale of children affected by AIDS by keeping children in school and} offering sports and recreational activities. This study links schooling to the happiness of both younger and older children. Since adult illness can cause children to drop out, program workers should tell families and guardians about the role of consistent schooling in sustaining children's morale through difficult transitions. On a policy level, primary and secondary school fees should be eliminated and school uniforms and supplies should be subsidized; this is critical in mitigating the educational and psychosocial impact of HIV/AIDS on children. Sports and recreation are other inexpensive but often overlooked activities that help to integrate children with their peers and maintain psychosocial wellbeing.

\section{Address stigmatization of and discrimination against AIDS-affected adults and}

children. Fear of disclosure limits parents' ability to appoint guardians and take other steps to secure their children's future. To reduce the stigma of AIDS, social service agencies should work to increase the sensitivity of community members, including children, to the needs of AIDSaffected children and their families. This should include communal efforts to monitor and reduce mistreatment of these children, such as teasing, neglect, and physical and sexual abuse. As innocuous as they may seem, teasing and gossip are widespread and painful manifestations of stigma directed at children affected by AIDS.

Involve future guardians in intervention efforts. Program workers should engage standby guardians in such intervention activities as income-generation projects and schedule special events when standby guardians who live far away are likely to visit, such as around holidays. Most standby guardians are male, but current guardians are predominantly female. Even if a male headof-household is named as the "official" guardian, women in standby guardian households should also be incorporated into interventions, because they are very likely to be raising orphans in the future. 


\section{Hgrizons}

\section{References}

AHRTAG. 1997. "Caring with confidence: Practical information for health workers who prevent and treat HIV infection in children.” AHRTAG Briefing Paper. London: AHRTAG.

Elmore-Meegan, Michael et al. 1999. "A comparison study of 646 children orphaned by AIDS (age 7-18) and 1,239 matched controls." Paper presented at the Collaborative Symposium on AIDS Research, January, Nairobi, Kenya.

Foster, Geoff et al. 1995. "Orphan prevalence and extended family care in a peri-urban community in Zimbabwe." AIDS Care 7(1): 3-17.

Foster, Geoff 1997. "AIDS and Child Health." Paper presented at the Homecare Conference, Amsterdam, the Netherlands, May 1997.

Foster, Geoff et al. 1997. "Factors leading to the establishment of child-headed households: The case of Zimbabwe." Health Transition Review 7 (Suppl): 155-68.

Haworth, A. et al. "Social Consequences of AIDS in 49 Zambian Families: A Descriptive Study." Paper presented at the VII International Conference on AIDS, Florence Italy.

Hunter, Susan and John Williamson. 1997. Children on the Brink: Strategies to Support HIV/AIDS. Washington: USAID.

Hunter, Susan and John Williamson. 2000. Children on the Brink Executive Summary: Updated Estimates and Recommendations for Intervention. Washington: USAID.

Kamali, A., J.A. Seeley, A.J. Nunn, J.F. Kengeya-Kayondo, A. Ruberantwari, and D.W. Mulder. 1996. "The orphan problem: Experience of a sub-Saharan Africa rural population in the AIDS epidemic." AIDS Care 8(5): 509-515.

Lusk, Diane, Sandra L. Huffman, and Chloe O'Gara. 2000. Assessment and Improvement of Care for AIDS-affected Children Under 5. Ready to Learn Project. Washington: Academy for Educational Development.

Monitoring the AIDS Pandemic (MAP) Network. 1998. "The status and trends of the HIV/AIDS epidemic in the world." Provisional report printed for the 13th International Conference on HIV/AIDS in Durban, South Africa.

Monk, Neil. 2000. Orphans of the HIV/AIDS Pandemic: A Study of Orphaned Children and their Households in Luweero District, Uganda. Unpublished research commissioned by the Associacion François-Xavier Bagnoud. 
Muller, O. and N. Abbas. 1990. "The impact of AIDS mortality on children's education in Kampala." AIDS Care (2) 1: 77-80.

Nalugoda, Fred et al. 1997. "HIV infection in rural households, Rakai District, Uganda." Health Transition Review 7 (Suppl. 2): 127-140.

Nampanya-Serpell, Nampoysa. 1998. "Children orphaned by HIV/AIDS in Zambia: Risk factors of premature parental death and policy implications." Unpublished doctoral dissertation, University of Maryland.

Ntozi, James P.M. and S. Zirimenya. 1999. "Changes in household composition and family structure during the AIDS epidemic in Uganda," in The Continuing African HIV/AIDS Epidemic: Responses and Coping Strategies, eds. I.O. Orubuloye, J. Caldwell, and J.P. Ntozi. Canberra: Health Transition Centre, pp. 193-209.

Reid, Elizabeth. 1993. "Children in families affected by the HIV epidemic: A strategic approach.” Issues Paper \#313. HIV and Development Program, United Nations Development Program. New York: UNDP.

Sengendo, J. and J. Nimbi. 1997. "The psychological effects of orphanhood: A study of orphans in Rakai district." Health Transition Review 7 (Suppl.): 105-124.

Shuey, Dean et al. 1996. "A community-based program for orphans and vulnerable children, Luwero district, Uganda: Strategies for implementation," in AIDS in the World, eds. J.M. Mann and D.J.M. Tarantola. New York: Oxford Press, pp. 283-285.

UNAIDS. 1999. "Children and HIV/AIDS.” UNAIDS Briefing Paper. Geneva, Switzerland.

UNAIDS. 2000. Report on the Global HIV/ AIDS Epidemic. Geneva, Switzerland.

Women and Law in East Africa (WLEA). 1997. "The Law of Succession Planning in Uganda: Women, Inheritance Laws and Practices: Essays and Cases." WLEA Publication \#1. WLEA: Kampala, Uganda. 